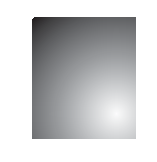

\title{
Geração de Renda e Educação na Base da Pirâmide Populacional: um estudo no município de São Paulo
}

\author{
Income generation and education at the Bottom of Pyramid: a
}

Renata Giovinazzo Spers

Professora Doutora do Departamento de Administração, Faculdade de Economia, Administração e Contabilidade - FEA - USP - São

Paulo - SP - Brasil. E-mail:renatag@usp.br

\section{Luciana Tiemi Nakandakare}

Faculdade de Economia, Administração e Contabilidade - FEA - USP - São Paulo - SP - Brasil. E-mail: lunakanda@gmail.com

\section{Resumo}

Este estudo tem como objetivo principal verificar se a educação está diretamente relacionada ao aumento da renda, tendo como foco a população da base da pirâmide. O trabalho pretende observar se é percebida por esta população a relevância da educação para aumento de sua renda e se esse seria um fator motivador para os estudos. Foi realizada uma pesquisa com base em dados secundários e por meio de uma survey com 120 respondentes da base da pirâmide. Os resultados mostram que a população da base da pirâmide entende a relevância da educação e seus impactos na renda atual e futura.

Palavras-chave: Base da Pirâmide. Educação. Evolução da Renda.

\section{Abstract}

This study has as main objective to verify if education is directly related to increased income, focusing on the population of the base of the pyramid in São Paulo. The paper aims to observe whether it is perceived by this population the relevance of education to increase their income and if this would be a motivating factor to increaser formal education. A research based on secondary data and through a survey with 120 respondents at the bottom of the pyramid. The results show that the population of the base of the pyramid understands the importance of education and its impact on current and future income.

Keywords: Base of Pyramid. Education. Evolution of Income. 


\section{INTRODUÇÃo}

Observa-se no Brasil, de modo geral, um aumento no poder aquisitivo e um crescimento da classe média da população, ao longo dos anos. Estudos indicam um caráter de mobilidade ascendente da população, sendo que entre 2010 e 2011, 2,7 milhões de brasileiros deixaram a classe $\mathrm{D}$ e $\mathrm{E}$ e mais de 230 mil entraram na classe $\mathrm{A}$ e B. Constata-se também um aumento da renda média disponível de aproximadamente $20 \%$ em relação aos resultados apresentados em 2011. Na classe $\mathrm{C}$, por sua vez, a renda média disponível cresceu quase $50 \%$, e a renda familiar média aumentou em torno de $8 \%$ no período. (CETELEM BGN; IPSOSPUBLIC AFFAIRS, 2011)

Estudo publicado pelo CPS/FGV (2012) mostra, além do crescimento da renda, a queda da pobreza e da desigualdade. Os índices de desigualdade mostraram diminuição, em 2011, de uma taxa quase duas vezes mais acelerada em relação aos primeiros anos da década de 2000.

Com essas melhorias na renda e na redução da pobreza e da desigualdade, também é possível observar um avanço no consumo da classe popular no Brasil. Além dos itens básicos de consumo, como alimentação, moradia, transporte, higiente e limpeza, também tem havido um aumento no consumo de produtos ligados a cuidados pessoais, carro próprio, moradia e educação. O alto índice de intenção de compra de imóveis exemplifica essa expansão de consumo das classes $C$, D e E. Dados de 2012 mostram que 11 milhões de famílias pertencentes à classe $\mathrm{C}$, que correspondem a $57,6 \%$ do estrato, pretendem comprar um imóvel nos próximos dois anos. A intenção da classe $\mathrm{D}$ e E, por sua vez, é de $27,2 \%$, ou 5,2 milhões de famílias. (CBIC, 2012)

Os gastos em educação ainda são relativamente pequenos nas classes $\mathrm{C}, \mathrm{D}$ e $\mathrm{E}$, mas tem aumentado e vem sendo cada vez mais valorizados ao longo do tempo. Esses gastos se refletem em uma redução do nível de analfabetismo e uma melhoria no grau de instrução da população, ainda que alguns índices ainda sejam relativamente ruins em comparação aos países desenvolvidos. Conforme dados do IBGE (2011), no Brasil, em 2000, 13,63\% das pessoas com mais de 15 anos de idade eram analfabetas. De 2000 para 2010, houve uma redução, chegando a 9,6\% em 2010, ou 14 milhões de analfabetos, nessa faixa etária. A redução é significativa, mas ainda há muitas oportunidades para melhoria dos índices de analfabetismo e grau de instrução da população brasileira.

Tendo em vista este contexto de mudança do ambiente socioeconômico que está ocorrendo no Brasil ao longo dos anos, com relação à população da base da pirâmide, pergunta-se: a educação é um fator que proporciona um aumento de renda para a população da base da pirâmide, sendo esse aumento um motivador para que se atribua maior importância aos estudos?

Dessa forma, este estudo tem como objetivo principal verificar se a educação está diretamente relacionada ao aumento da renda, tendo como foco a população da base da pirâmide. Também tem por objetivo verificar se há uma percepção, por parte da população da base da pirâmide, sobre a relevância da educação para aumento de sua renda e se esse seria um fator motivador para os estudos.

Cabem algumas definições relevantes com relação à pergunta de pesquisa e objetivos do trabalho, a saber:

a) No contexto deste estudo, educação refere-se à educação formal, oferecida por escolas públicas ou privadas, não sendo considerados estudos relacionados a leituras ou outras formas de aprendizagem autodidatas.

b) Considera-se base da pirâmide social aquela composta pelas pessoas mais pobres da população. De acordo com critério proposto pelo IBGE, a base da pirâmide é composta pelas classes C, D e E. No Brasil, ela é constituída por famílias que possuem renda mensal média familiar abaixo de dez salários mínimos. Para a operacionalização da pesquisa foi considerado o valor equivalente a $\mathrm{R} \$ 5.174$ (DOUAT, 2011), para a população com renda abaixo de dez salários mínimos, tendo em vista a realização da pesquisa de campo em 2012. Para fins do estudo será analisada a população de baixa renda do município de São Paulo.

c) A renda refere-se a salários provenientes de atividade com carteira assinada, ou outros rendimentos oriundos de atividades informais (sem carteira assinada).

Considerando os objetivos do trabalho, são traçadas seis hipóteses a serem verificadas com base na 
teoria e na pesquisa de campo, conforme detalhado nos próximos itens deste artigo. Foram definidas as seguintes hipóteses:

a) H0: A população da base da pirâmide tem conhecimento da relação entre uma maior renda e a quantidade de educação adquirida (anos de estudo).

b) H1: A população de baixa renda reconhece a importância da educação.

c) H2: O aumento de renda proporcionado pelo maior nível educacional é um motivador para que se dê maior importância aos estudos pela população da base da pirâmide.

d) H3: As pessoas de baixa renda pretendem retomar/continuar os estudos depois de adultos, devido ao aumento de renda proporcionado pelo maior nível educacional.

e) H4: A população da base da pirâmide acredita na relação entre educação $e$ melhores empregos.

f) H5: A expectativa da população de baixa renda para os próximos anos é que suas condições de vida melhorem de acordo com a dedicação aos estudos.

g) H6: As pessoas de baixa renda exigem que seus filhos estudem, devido ao aumento de renda proporcionado pelo maior nível educacional.

Para atender aos objetivos do estudo, foram realizadas pesquisas em duas etapas: uma primeira etapa de análises com base em dados secundários, com vista a traçar um diagnóstico sobre a base da pirâmide e a educação no Brasil e em São Paulo, assim como identificar algumas relações iniciais entre renda e educação. Em ums segunda etapa, foi feita uma análise com base em dados primários para compreensão do comportamento da população da base da pirâmide de São Paulo, referente à educação e expectativas, e relacionando-as ao nível de renda.

A partir da exploração do tema nas duas vertentes, conclui-se o estudo, aceitando ou rejeitando as hipóteses apresentadas, de acordo com as análises e relações realizadas. Sendo o foco do trabalho a população da base da pirâmide do município de São Paulo. Essa premissa fará com que o estudo seja mais condizente com a realidade em níveis de extrapolação, tendo em vista que o levantamento de dados primários foi realizado nesta localidade.

\section{Base da Pirâmide: fundamentos, CARACTERÍ́sticas E EXPECTATIVAS PARA O}

\section{FUTURO}

Como o foco do trabalho é a base da pirâmide, torna-se necessário alinhar o entendimento desse conceito. Será adotado o critério de segmentação de classes econômicas do IBGE, por ser amplamente utilizado no Brasil, além de representar uma fonte confiável. A divisão é realizada de acordo com a renda média mensal das famílias, em salários minímos, resultando em cinco classes. Pode ser feita uma relação de salários mínimos para renda em reais, com dados de 2011, conforme segue: a classe A é composta por famílias com renda mensal acima de $\mathrm{R} \$ 6.745$; a classe $\mathrm{B}$, por famílias com renda entre $R \$ 5.174$ e $R \$ 6.745$; o estrato $C$, com renda entre $R \$ 1.200$ e $R \$ 5.174$; a camada $D$ apresenta renda mensal entre $R \$ 751$ e $R \$ 1.200$; e a classe $\mathrm{E}$ tem renda abaixo de $\mathrm{R} \$ 751$ (DOUAT, 2011). As classes C, D e E correspondem aos indivíduos mais pobres da população, a base da pirâmide.

Wright e Spers (2011) destacam que a base da pirâmide é um grupo de consumidores em potencial que, se fizerem parte do mercado consumidor, podem gerar muita riqueza e, consequentemente, inclusão $e$ bem-estar social.

De acordo com dados publicados pelo CPS/FGV (2012), em 2011, as classes A e B correspondiam a $12 \%$ da população brasileira, a classe $C$ compreendia $55 \%$, e as D e E, 33\%. Para 2014, projeta-se que as camadas mais altas aumentarão sua participação relativa na pirâmide, englobando $15 \%$ da população; o estrato médio sofrerá crescimento também, totalizando $60 \%$, e as classes mais baixas corresponderão a $25 \%$.

A mudança na estrutura socieconômica brasileira deveu-se a uma melhor distribuição de renda e ao aumento da renda média da população. De acordo com análise realizada por Wright e Cardoso (apud SPERS; WRIGHT, 2006) observou-se crescimento no número de famílias com rendimento médio mensal entre dois e cinco salários mínimos no período de 1992 a 2004. $\mathrm{O}$ aumento da renda familiar provocou a transição de elementos da classe $\mathrm{D}$ e $\mathrm{E}$ para a $\mathrm{C}$, ao longo dos anos. As classes C, D e E, juntas, representavam $88 \%$ da população total em 2011. (CPS/FGV, 2012) 
Nesse cenário, em que a maioria da população pertence à base da pirâmide, deve-se despender maior atenção aos bens populares e essenciais para atender o mercado de baixa renda. Bens populares têm como público-alvo as classes de renda C, D e E (GIOVINA$\mathrm{ZZO}, 2003)$. Em pesquisa realizada por Spers e Wright (2006), com 75 empresas dos setores de alimentos, bebidas, higiene e limpeza, vestuário, bens eletrônicos e comércio varejista, durante cinco anos, traçou-se um perfil estratégico para empresas focadas no mercado popular. Identificou-se, então, que esse público da base da pirâmide prefere produtos e serviços mais simples e padronizados, com poucos produtos e serviços agregados, porém, é necessário que tenham qualidade e estejam disponíveis a preços adequados.

O consumo na base da pirâmide tem crescido, considerando as preferências deste grupo quanto aos produtos e serviços. O mercado de cartão de crédito representa outra tendência que tem crescido no segmento de baixa renda, pois o crédito possibilita o acesso do consumidor aos bens de consumo. (DATA POPULAR, 2006; SPERS et al., 2008)

Outra tendência importante refere-se ao fato do consumidor de baixa renda ter a necessidade de inclusão social, em contraposição com o consumidor das classes mais altas, que querem ser exclusivos. Os consumidores mais pobres já se sentem excluídos, à margem da sociedade, sentem-se inferiorizados. $\mathrm{O}$ consumo, por sua vez, oferece uma ideia de pertencimento do grupo, é uma forma de sentir-se parte integrante da sociedade. Consumir faz bem para a autoestima desse tipo de consumidor. (OLIVEIRA, 2006)

Com relação à composição da base da pirâmide, segundo o Data Popular (2006), há o predomínio de jovens, sendo que $30 \%$ da classe C é composta por pessoas com menos de 20 anos e nas classes $\mathrm{D}$ e E, a porcentagem é de $41 \%$. Essa relação impacta significativamente na economia, e destacam-se oportunidades em alguns segmentos de produtos, entre eles a educação, que é foco deste estudo.

Na população da base da pirâmide, grupos que exercem influência direta são os de grupos de afinidade, que consistem de amigos, vizinhos, familiares e colegas de trabalho (MELLO; OLIVEIRA; SOUZA, 2008). A relação dessas pessoas é importante e se reflete no consumo, pois informalmente são passadas informações sobre produtos e serviços. Essas informa- ções podem promover ou prejudicar a imagem de uma marca, serviço ou produto.

Algumas características referentes ao comportamento dos indivíduos da base da pirâmide foram destacadas, contextualizando o estrato da população que será foco do trabalho.

O Instituto de Pesquisa Econômica Aplicada (IPEA) realiza pesquisa mensal em mais de 200 municípios da federação e confecciona o Índice de Expectativa das Famílias (IEF). Segundo a pesquisa, o brasileiro manteve-se otimista em todo o período entre fevereiro/2011 e fevereiro/2012 (IPEA, 2012). Todos os graus de escolaridade e renda apresentaram elevadas expectativas para uma melhor situação financeira da família para o ano seguinte. No âmbito da escolaridade, as pessoas sem instrução são as menos otimistas, com $10,4 \%$ de expectativa de melhora, as que possuem nível médio incompleto apresentam grande otimismo, com $92,2 \%$. Em relação à faixa salarial, os indivíduos mais pessimistas são os que recebem até um salário mínimo mensal, já os mais otimistas são os que recebem de cinco a dez salários mínimos.

Pode-se constatar, então, que, de maneira geral, os brasileiros enxergam o futuro com otimismo. Contudo, as pessoas de menor escolaridade e as que recebem menor salário, mostram-se mais pessimistas, pois não veem, no futuro, possibilidade de melhorar suas condições de vida.

\subsection{Renda e Desigualdade Social e Programas Sociais}

O Instituto de Pesquisa Econômica Aplicada (IPEA, 2012) disponibilizou dados comparativos entre o Brasil, a região Sudeste e o Estado de São Paulo, no período de 2001 a 2009, referentes à renda, desigualdade social e situação de extrema pobreza. De acordo com o relatório, no Brasil, o poder aquisitivo da população obteve um aumento real de $23,5 \%$ entre os anos de 2001 e 2009, considerando que no primeiro ano, a renda domiciliar per capita média era de $\mathrm{R} \$ 511,5$, e no último ano era de $\mathrm{R} \$ 631,7$. Em São Paulo, em 2001, a renda domiciliar per capita tinha média de $\mathrm{R} \$ 738,2$, e em 2009 , de $\mathrm{R} \$ 806,9$, resultando, portanto, em um aumento de 9,3\% no período, abaixo do percentual nacional. Mesmo assim, os valores absolutos de São Paulo são superiores à média do país. 
Os programas sociais do governo também têm importante papel para a redução das desigualdades sociais no Brasil, melhorando o acesso da população da base da pirâmide ao consumo. Políticas sociais são mecanismos propostos pelo Estado e visam melhorar as condições básicas de vida de uma sociedade. No Brasil, a política social corresponde a uma fração considerável do gasto público. Grande parte desse gasto social tem um duplo benefício, ele promove o crescimento da economia e, ao mesmo tempo, melhora a distribuição de renda e de capacidades, pois ele é realizado, em sua grande maioria, favorecendo os estratos mais pobres. (IPEA, 2011)

Um dos principais programas de desenvolvimento social atuais do governo é o programa Bolsa Família. Segundo publicação do International Policy Centre for Inclusive Growth, o programa Bolsa Família fornece auxílio financeiro às famílias pobres do Brasil, porém, impõe uma condição: as crianças devem frequentar a escola. Objetiva-se, assim, reduzir a pobreza, a curto e longo prazos, através de transferências condicionadas de capital, e acabar com a transmissão da miséria ao longo das gerações, interrompendo o círculo vicioso (MAIA, 2008). Em se tratando de transferência de renda, o programa Bolsa Família foi o que obteve o maior multiplicador do PIB e da renda das famílias. Para cada $\mathrm{R} \$ 1,00$ gasto no programa, o PIB aumenta em $R \$ 1,44$ e a renda das famílias em 2,25\%, após percorrido todo o circuito de multiplicação de renda na economia. (IPEA, 2011)

O governo, muitas vezes, como não possui recursos suficientes para arcar com todo o ônus da manutenção de programas de desenvolvimento, associa-se a outras entidades. Prahalad (2008) defende que para gerar riqueza e desenvolvimento social na base da pirâmide é necessário que haja uma relação simbiótica entre diversas entidades sociais, como organizações não governamentais (ONGs), cooperativas e empresas. Essa interação visa desenvolver mercados, criando produtos e serviços que possuam valor para o consumidor de baixa renda.

Segundo Spers, Victor e Fischer (2010), a distribuição de renda e o desenvolvimento de comunidades podem ser alcançados, porém, na maioria das vezes são necessárias ações conjuntas entre entidades públicas e particulares para que melhorias aconteçam.

\subsection{Relação entre Educação e Renda}

Segundo Schultz (1963, apud ZIMMER, 2011), em sua Teoria do Capital Humano, a educação é definida como um investimento, e suas consequências como uma forma de capital. O autor defende, então, que a educação é um investimento realizado com a finalidade de adquirir capacitações que ofereçam satisfação futura ou que incrementem rendimentos futuros de uma pessoa como agente produtivo. Assim, aplicando a Teoria do Capital Humano para o nível do indivíduo, entende-se que investir em educação é motivado pelo maior nível de retorno, de renda.

Barbosa Filho e Pessôa (2008) realizaram análise calculando a taxa de retorno da educação no Brasil por meio da Taxa Interna de Retorno (TIR). Notou-se que as taxas de retorno da educação são extremamente elevadas no Brasil, o que significa que ganhos de salário associados aos anos de escolaridade são expressivos, tornando o investimento nessa área bastante atrativo.

A relação positiva entre educação $e$ renda, no Brasil, foi comprovada por estudo realizado pelo IPEA (2011). Por meio de simulações, constatou-se que, no que tange ao multiplicador do Produto Interno Bruto (PIB), a educação é o gasto público social que mais contribui para o crescimento do PIB. Tudo o mais constante, a cada $\mathrm{R} \$ 1,00$ gasto com educação pública é gerado $\mathrm{R} \$ 1,85$ em PIB e $\mathrm{R} \$ 1,67$ em renda. Isso ocorre devido ao processo de multiplicação de renda que a educação propicia, movimentando a economia.

Segundo resultados do IBGE de 2002/2003, há relação entre o número de anos de estudo e a renda familiar, sendo a educação o instrumento mais efetivo para reduzir as desigualdades sociais. A renda familiar obtinha um aumento significativo se ao menos um membro da família possuísse nível universitário, passando de $R \$ 1.215,24$ para $R \$ 3.817,96$ de renda média anual. Se na família existissem pelo menos duas pessoas com curso universitário, a renda média passava para $\mathrm{R} \$ 6.994,98$. (CNTE apud VALOR ECONÔMICO, 2007)

De acordo com o Data Popular (2006), a base da pirâmide é menos escolarizada que a elite brasileira, porém, nota-se uma tendência de aumento da média dos anos de escolaridade das classes populares. E a juventude das classes mais baixas está ficando mais educada. Dados históricos do IPEA (2009) indicam 
que houve aumento, ao longo dos anos, da renda domicilar mensal per capita média dos brasileiros pobres. Desse modo, é possível que o crescimento da renda da população mais pobre seja, mesmo que em parte, devido ao aumento de escolaridade.

Portanto, conclui-se que existe, de fato, uma relação positiva entre escolaridade e renda da população no Brasil. Isso foi possível ser constatado por meio da Teoria do Capital Humano apresentada e de estudos empíricos realizados por institutos de pesquisa.

Após analisar a relação entre renda e educação do ponto de vista teórico e pesquisas realizadas no Brasil, é interessante observar a relação desses fatores no Estado de São Paulo, visando um embasamento para a pesquisa empírica feita em seguida.

Ao se observar o histórico da renda domiciliar per capita média da população total do Estado de São Paulo na Figura 1, pode-se notar que, apesar de oscilações ao longo dos anos, houve incremento real de $R \$ 185,62$, o que equivale a um aumento de $26 \%$ de 1981 até 2009. Considerando que a renda domicilar média per capita em 1981 era de $\mathrm{R} \$ 714,80$, e em 2009 , de $\mathrm{R} \$ 900,42$. A quantidade média de anos de estudo, por sua vez, sofreu variações mais acentuadas que a renda. Em 1981, a média de anos de estudo para pessoas com 25 anos de idade ou mais era de 4,66, já em 2007, que foi o último ano em que esse dado foi disponibilizado, era de 7,94 anos, resultando em um aumento de $70 \%$ no período.

A taxa de analfabetismo descreve o comportamento dos paulistas com 15 anos de idade ou mais entre os anos de 1981 e 2009. O analfabetismo apresentou significativa redução, sendo que no primeiro ano analisado a taxa era de $12,52 \%$, e no último, de $4,61 \%$, havendo, então, uma redução de aproximadamente $63 \%$ no período. (IPEA, 2009)

Pode-se concluir, a partir dos dados apresentados, que, no período entre 1981 e 2009, questões relacionadas à educação obtiveram grandes mudanças benéficas à população, considerando o aumento da quantidade de anos de estudos e a vultosa diminuição da taxa de analfabetismo. Foi importante também o aumento da renda domicilar per capita média, contudo, o crescimento desta variável não foi tão significativo quanto os melhoramentos apresentados na educação.

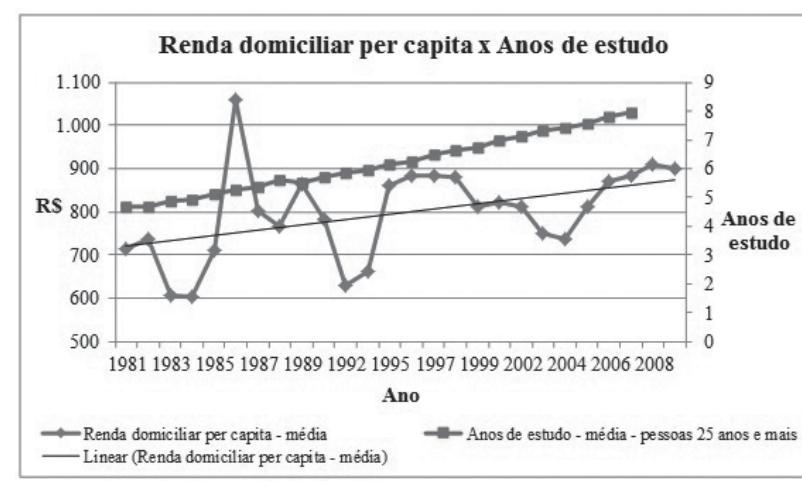

Figura 1: Renda domiciliar per capita x Anos de estudo Fonte: Elaborada pelos autores deste artigo a partir de dados do Ipeadata (2009)

Os elementos analisados a partir dos dados secundários geraram as variáveis para a pesquisa de campo para coleta de dados primários, cuja aplicação será apresentada no item de metodologia a seguir. E posteriormente será apresentada análise dos resultados obtidos a partir da aplicação da pesquisa de campo.

\section{Metodologia Aplicada no Estudo}

A pesquisa deste trabalho é classificada como exploratória descritiva. Segundo Malhotra (2004), é desejável começar com a pesquisa exploratória quando pouco se sabe a respeito da situação-problema, para que seja possível maior aprofundamento no tema, $e$ assim definir mais precisamente o problema. Então, primeiramente, foram analisados os dados secundários com o intuito de conhecer mais a fundo os temas que serão abordados, como os assuntos que envolvem a expectativa de aumento da renda e o comportamento da base da pirâmide em relação à educação. Os dados secundários foram obtidos a partir de fontes públicas governamentais e de artigos acadêmicos que abordaram temas semelhantes.

A pesquisa exploratória possibilitou fundamentação para que fosse realizada a pesquisa descritiva. A pesquisa descritiva tem como objetivo estimar a porcentagem de unidades em uma população específica que exibe um determinado comportamento $e$ fazer previsões específicas (MALHOTRA, 2004). Essa parte do estudo foi realizada quantitativamente, por meio de uma pesquisa do tipo survey, com a aplicação de questionário estruturado para a coleta de dados primários com a amostra, no município de São Paulo. 
A elaboração do questionário foi norteada pelos objetivos e hipóteses do trabalho e baseada nas informações obtidas na pesquisa com os dados secundários. As seguintes variáveis nortearam a confecção do questionário: idade, nível educacional e de renda dos respondentes, importância conferida à educação, a relação desta com a renda e expectativas futuras. As variáveis de idade, grau de instrução e renda, além de qualificarem o respondente, possibilitaram cruzar as informações, comprovando as relações apresentadas nos dados secundários, como a maior instrução das pessoas mais novas em oposição à escolaridade das mais velhas. As pretensões futuras de dar continuidade ou não aos estudos e a exigência em relação aos filhos neste quesito verificaram a importância conferida à educação. A relação percebida pela população-alvo entre renda e educação pode ser obtida ao indagar aos indivíduos se quanto mais a pessoa estudar, melhor será seu emprego. Essas variáveis estão relacionadas à Teoria do Capital Humano (SCHULTZ, 1963, apud ZIMMER, 2011) apresentado no referencial teórico. A variável referente às expectativas futuras, estudada no Índice de Expectativa das Famílias (IPEA, 2012) e exposta anteriormente neste trabalho, foi abrangida por meio de perguntas que envolvem as condições de vida esperadas para o futuro pelos respondentes.

Segundo o método apresentado por Lopes (2003), o tamanho da amostra a ser pesquisada deveria ser de, no mínimo, 119 questionários válidos, como demonstrado na fórmula a seguir, considerando a principal variável nominal e uma população finita:

$$
n=\frac{z^{2} * p * q * N}{d^{2} *(N-1)+z^{2} * p * q}=119 \text { pesquisas }
$$

(Onde: $\mathrm{Z}$ = abcissa da normal padrão; $\mathrm{N}=$ tamanho população; $p=$ estimativa da proporção de um dos níveis da variável escolhida; $\mathrm{q}=1-\mathrm{p} ; \mathrm{d}=$ erro amostral)

O tamanho da população considerada foi de 2.763.650, sendo esse o número de domicílios particulares permanentes existentes no município de São Paulo com rendimento domiciliar mensal abaixo de dez salários mínimos, o equivalente a $\mathrm{R} \$ 5.174$ mensais - a chamada base da pirâmide neste trabalho - segundo dados do Censo Demográfico de 2010 (IBGE, 2010). Foi considerado um nível de significância de 95\%, sendo $Z$, então, 1,96. O valor p utilizado foi de 0,50 e q é 0,50 também. Já o erro amostral foi de $9 \%$. Dessa forma, o número mínimo de questionários a serem coletados foi definido como 119.

Antes da aplicação efetiva da pesquisa foi realizado um pré-teste com cinco pessoas com o perfil adequado ao estudo, com o intuito de corrigir possíveis erros e dubiedades das perguntas. Após a aplicação e análise do pré-teste, o questionário foi ajustado. Com relação à amostra, adotou-se uma amostra intencional, com parte dos respondentes selecionada devido à possibilidade de acesso, por meio de pessoas conhecidas no município de São Paulo. Outra parte das informações foi coletada em terminais de ônibus, na zona norte da cidade, e na estação do metrô Sé, localizada no centro de São Paulo, de forma aleatória. A escolha desses locais deveu-se, primeiramente, ao objetivo de encontrar indivíduos das classes sociais C, D e E, mas também, de alcançar um maior volume de pessoas com disponibilidade para responder às perguntas. Como resultado, foram coletadas 138 respostas, sendo 120 válidas e 18 impossibilitadas de serem utilizadas devido à restrição da renda familiar mensal, que deveria ser inferior a $\mathrm{R} \$ 5.174$, ou então, por motivos de preenchimento incorreto do questionário.

O número de questionários válidos tornou, portanto, o estudo viável. E na próxima etapa do trabalho, são demonstradas as análises dos dados primários obtidos, aceitando ou rejeitando as hipóteses propostas inicialmente no estudo. São também comparados os resultados obtidos na pesquisa quantitativa com os dados secundários. Por fim, as limitações e as sugestões para pesquisas futuras sobre o tema são apontadas.

\section{Análise dos Resultados da Pesquisa}

Ao analisar as respostas obtidas na pesquisa de campo, primeiramente, foi observado o perfil dos respondentes. A maior parte dos entrevistados era mulheres, representando $67 \%$, e os homens, $33 \%$ do total. Quanto à idade, obteve-se resposta de pessoas que têm de 15 a 65 anos, dentre elas aproximadamente metade se encontra na faixa etária entre 15 e 25 anos.

Foram consideradas válidas as pesquisas nas quais os indivíduos responderam que suas rendas familiares mensais eram inferiores a $R \$ 5.174$, pois o foco deste estudo é a base da pirâmide social, que corresponde às classes $\mathrm{C}, \mathrm{D} e \mathrm{E}$, como apresentado 
anteriormente. Houve resposta para essas três classes sociais, sendo $3 \%$ dos respondentes da classe $\mathrm{E}$ (renda familiar mensal inferior a $\mathrm{R} \$ 751$ ), $27 \%$ pertencentes à classe $\mathrm{D}$ (renda familiar mensal entre $\mathrm{R} \$ 751$ e $\mathrm{R} \$$ 1.200 ) e $70 \%$ das pessoas são da classe $C$ (renda familiar mensal entre $\mathrm{R} \$ 1.200$ e $\mathrm{R} \$ 5.174)$.

Em relação ao grau de escolaridade dos pesquisados, todas as pessoas estudaram em algum grau. É importante destacar que a maior parte $(38 \%)$ cursou até o Ensino Médio. O Ensino Superior, completo ou incompleto, correspondeu a $28 \%$ do nível educacional encontrado. E recebeu o menor número de respostas a faixa que corresponde à menor escolaridade, até $1^{\mathrm{a}}$ série do Ensino Fundamental, sendo essa realidade positiva para o município de São Paulo.

As pessoas de mais idade possuem grau de instrução menor que as mais novas. $100 \%$ dos indivíduos com 65 anos ou mais estudaram até o Ensino Fundamental, assim como grande parte das pessoas com idade entre 35 e 65 anos. Contudo, uma parcela dessas pessoas de 35 a 65 anos estudou até o Ensino Médio ou até mesmo o Superior. Na faixa dos 25 a 35 anos, a porcentagem de respostas no nível do Ensino Fundamental reduziu, e foi aumentada a do Ensino
Médio e do Superior em relação às outras faixas etárias, sendo $37 \%$ e $22 \%$, respectivamente. Essa tendência foi expressiva para os indivíduos de 15 a 25 anos, em que apenas $16 \%$ das pessoas desse intervalo cursaram até o Ensino Fundamental, e se elevaram significativamente os índices do Ensino Médio e Superior, com $45 \%$ e $39 \%$, respectivamente.

Tais fatos corroboram a informação apresentada no referencial teórico, de que houve aumento da média de anos de escolaridade das classes populares, $e$ a juventude das classes mais baixas está ficando mais educada. (DATA POPULAR, 2006)

Encontrou-se também uma relação entre as variáveis renda e escolaridade para a população. Como pode ser observado na Tabela 1, considerando a faixa de rendimento abaixo de $\mathrm{R} \$ 751$, não há citação referente a pessoas que cursaram o Ensino Superior e que se encontrem nesta classe $E$. Das pessoas que possuem renda mensal entre $R \$ 751$ e $R \$ 1.200$, rendimento correspondente à classe $\mathrm{D}$, a maior parcela estudou até o Ensino Fundamental (completo ou não). Observando-se a classe $\mathrm{C}$, a que possui maior renda neste trabalho, seus indivíduos são mais escolarizados, tendo maior participação nos Ensinos Médio e Superior.

Tabela 1: Renda x Escolaridade na Base da Pirâmide

\begin{tabular}{|l|r|r|r|r|r|r|r|}
\hline \multicolumn{7}{|c|}{ Renda x Escolaridade } \\
\hline $\begin{array}{l}\text { até 1a } \\
\text { EF }\end{array}$ & $\begin{array}{c}\text { entre 2a } \\
\text { e 5a EF }\end{array}$ & $\begin{array}{c}\text { entre 6a } \\
\text { e 8a EF }\end{array}$ & $\begin{array}{c}\text { entre 1a } \\
\text { e 3a EM }\end{array}$ & $\begin{array}{c}\text { ES } \\
\text { Incompl. }\end{array}$ & $\begin{array}{c}\text { ES } \\
\text { Compl. }\end{array}$ & Total \\
\hline $\begin{array}{l}\text { Renda menor que } \\
\text { RS 751 }\end{array}$ & $0 \%$ & $75 \%$ & $0 \%$ & $25 \%$ & $0 \%$ & $0 \%$ & $100 \%$ \\
\hline $\begin{array}{l}\text { Renda entre } \\
\text { RS751 e R\$1200 }\end{array}$ & $13 \%$ & $13 \%$ & $19 \%$ & $34 \%$ & $9 \%$ & $13 \%$ & $100 \%$ \\
\hline $\begin{array}{l}\text { Renda entre } \\
\text { RS1200 e RS5174 }\end{array}$ & $2 \%$ & $7 \%$ & $19 \%$ & $39 \%$ & $15 \%$ & $17 \%$ & $100 \%$ \\
\hline \multicolumn{1}{|c|}{ Total } & $\mathbf{5 \%}$ & $\mathbf{1 1} \%$ & $\mathbf{1 8} \%$ & $\mathbf{3 8} \%$ & $\mathbf{1 3} \%$ & $\mathbf{1 5 \%}$ & $\mathbf{1 0 0 \%}$ \\
\hline
\end{tabular}

* EF - Ensino Fundamental; EM - Ensino Médio; ES - Ensino Superior

Fonte: Elaborada pelos autores deste artigo

Portanto, esses dados mostram correlação positiva entre renda e o nível de escolaridade. E está de acordo com o que foi apresentado no referencial teórico sobre número de anos de estudo e a renda familiar, sendo a educação um instrumento eficaz para diminuir as desigualdades sociais. (CNTE apud VALOR ECONÔMICO, 2007)
Em seguida, indagou-se às pessoas se elas achavam importante estudar, $98 \%$ responderam "sim" à pergunta e $2 \%$ responderam que não. Dessa forma, a hipótese de que "A população de baixa renda entende a importância da educação" foi comprovada. Para conhecer a percepção e a realidade na qual as pessoas da base da pirâmide estão inseridas, buscou-se também entender se a necessidade de trabalhar impossibilita 
que elas estudem. $58 \%$ dos respondentes disseram que se não tivessem que trabalhar para garantir seu sustento, eles estudariam. Contudo, essas pessoas não têm tempo suficiente para se dedicar ao trabalho, estudose outros afazeres, como cuidar da casa e dos filhos. Dessa forma, os estudos ficam em segundo plano.

Por outro lado, $17 \%$ das pessoas entrevistadas não estudariam, nem mesmo se não precisasem trabalhar. E $26 \%$ disseram que a frase "se não tivesse que trabalhar, eu estudaria" não se aplica à realidade delas, pois elas estudam e trabalham, logo um não impossibilita o outro.

Para as pessoas que concordaram que se não tivessem que trabalhar, elas estudariam, foi perguntado qual seria, então, o objetivo delas, em relação aos estudos. $57 \%$ afirmaram que gostariam de fazer uma faculdade, em seguida, com $27 \%$, foi citada a categoria "outros cursos", como os profissionalizantes, de idiomas ou de aperfeiçoamento. Para os que não estudariam mesmo se não necessitassem trabalhar, apenas $6 \%$ disseram que o motivo disso seria que mais estudo não mudaria em nada suas vidas. Contudo, para a maior parte, $94 \%$, existem outros motivos, como por não gostarem de estudar ou se acharem muito velhos para conseguirem se readaptar e retornar aos estudos.

Assim, a hipótese "As pessoas da base da pirâmide estudariam, se não precisassem trabalhar." não foi comprovada, pois neste ponto, as características pessoais de cada um têm maior peso. Não importa apenas se a pessoa possui a oportunidade de estudar, mas sim de sua real vontade, determinação e o contexto em que se encontram.

Mesmo dentre aqueles que responderam que é importante estudar, alguns afirmaram também que não retomariam os estudos. Isto não é uma contradição, pois as pessoas compreendem a importância dos estudos, porém acreditam que não conseguiriam voltar a frequentar a escola.

A opinião dos respondentes sobre a importância dada à educação, em grande parte, é formada pela crença de que melhores salários e empregos advêm do maior conhecimento adquirido nos estudos. $66 \%$ das respostas indicam haver relação entre quanto mais anos de estudo tiver, maior será o salário do indivíduo; contra $34 \%$, que não acreditam na relação. E para a afirmação de que quanto mais estudo, melhor será o emprego ou cargo, a porcentagem que concorda aumenta para $74 \%$.

Essas percepções obtidas na pesquisa são explicações plausíveis para os dados secundários levantados no referencial teórico a respeito da evolução da renda e da educação no Estado de São Paulo. Assim, um maior grau de instrução implica em maior salário $e$ melhor emprego. Essa relação e a busca de ascensão motiva os indivíduos, ao longo dos anos, a incrementar o nível educacional.

Após entender a realidade em que os indivíduos estão inseridos no momento, julga-se interessante confrontar a realidade com as expectativas e planos para o futuro. Observou-se que $54 \%$ das pessoas não estão estudando e já faz tempo que pararam de estudar, porém, $86 \%$ do total, que correspondem a $75 \%$ daquelas que não estudam no momento, pretendem continuar ou retomar os estudos nos próximos anos.

Ainda comparando o passado, presente e as expectativas futuras, $77 \%$ das pessoas disseram que suas condições de vida em relação ao passado melhoraram, de maneira geral. Para a maior parte delas, atualmente, há mais recursos para se gastar em atividades e produtos não essenciais ou para poupar, do que no passado. E é esperado que no futuro esse progresso continue, $57 \%$ das respostas mostram-se otimistas e têm expectativas de que as condições, ao longo dos anos, irão melhorar muito. Houve pouquíssimas respostas de piora acentuada das condições de vida do passado para hoje, correspondendo a apenas $2 \%$. E não apareceu citação de que se espera que as condições futuras piorem muito no futuro.

Ao cruzar os dados referentes à renda mensal familiar dos respondentes com as expectativas futuras expressas por eles, nota-se que há poucas citações da classe C (renda entre $R \$ 1.200$ e $R \$ 5.174$ ) que indiquem piora de condições. De acordo com o comportamento geral da classe $C$, são os respondentes mais otimistas em relação às condições de vida no futuro, com $61 \%$ dizendo que nos próximos anos terão um poder de consumo muito maior, $31 \%$ acreditam que a situação será um pouco melhor, e $11 \%$ afirmam que não haverá mudanças significativas.

Já a classe $\mathrm{D}$ (renda entre $\mathrm{R} \$ 751$ e $\mathrm{R} \$ 1.200)$, também tem uma visão positiva de seu futuro, com $50 \%$ dos indivíduos acreditando que suas condições irão melhorar muito, $31 \%$ dizem que melhorarão um 
pouco e $19 \%$ deles acham que suas vidas continuarão como estão. A classe $\mathrm{E}$, que possui renda familiar mensal abaixo de $\mathrm{R} \$ 751$, é a menos otimista, com metade do total dos indivíduos acreditando que as condições de vida não se alterarão nos próximos anos. E os que esperam que as condições vão melhorar muito $e$ um pouco corresponde a $25 \%$ deles.

Portanto, foram encontradas conclusões semelhantes para o município de São Paulo em comparação com a Pesquisa de Índice de Expectativas das Famílias (IPEA, 2012), a qual, apresentada no referencial teórico, retrata o Brasil inteiro. Apesar de todos os estratos se mostrarem otimistas em relação ao futuro, no âmbito da renda, os de visão mais positiva são aqueles que possuem renda mais elevada, e os menos otimistas são os de menor renda. Como muitas pessoas pretendem continuar ou retomar seus estudos nos anos em que se seguem, e devido a isso, elas esperam melhorar suas condições de vida. Essa é uma explicação para que sejam tão positivas ao visualisar o futuro.

Pode-se também conhecer a real importância que as pessoas auferem aos estudos, e se elas relacionam uma maior educação com uma vida melhor, ao observar o que esperam dos filhos.

Dentre os entrevistados, a maior parte, $52 \%$ não têm filhos, 39\% deles têm filhos e estudam, e 9\% têm filhos, mas não estudam. Considerando as pessoas que têm filhos, mas que estes não estudam, procurou-se saber os motivos de os filhos não frequentarem a escola. Em $64 \%$ das pesquisas foi assinalado o motivo "outros", neste caso, enquadram-se, em sua maioria, os bebês ou crianças muito pequenas que ficam em casa, e por isso não estudam ainda. E com $9 \%$ ficam empatadas as outras causas, que são basicamente a opção dos próprios filhos de não estudar. Há também casos em que os filhos dos respondentes já completaram o Ensino Superior, e, assim, resolveram parar os estudos.

Foi indagado aos entrevistados, até que grau de escolaridade para eles seria imprescindível que seus filhos alcançassem. Aos que não tinham filhos, foi pedido para que respondessem caso tivessem. $48 \%$ das pessoas gostariam que seus filhos fizessem uma faculdade, $35 \%$ disseram que fariam seus filhos completar ao menos até o Ensino Médio, depois ficaria a critério de cada um cursar ou não uma faculdade. Apenas $9 \%$ dos pais obrigariam os filhos a estudar até terminar o Ensino Fundamental, e 8\% puderam interromper os estudos quando quisessem, independentemente da série em que estivessem.

É nesse aspecto que o governo interfere ao exigir a frequencia escolar para as crianças das famílias auxiliadas no programa social Bolsa Família. Esse programa, como exposto no referencial teórico, é um dos principais programas do governo que visa o desenvolvimento da sociedade e tem como objetivo ajudar financeiramente as famílias pobres do país, mas, em contrapartida, requere que as crianças frequentem a escola. (MAIA, 2008)

Portanto, ficou comprovado que os indivíduos residentes no município de São Paulo acreditam na importância da educação, sendo o governo um dos principais promotores deste comportamento nas classes menos abastadas. Essa valorização é observada nos planos futuros de continuação ou retomada dos estudos por parte das pessoas e pela atitude que elas têm em relação aos seus filhos. É importante também ressaltar que a motivação advém da vontade de incrementar a renda e/ou melhorar de emprego e, consequentemente, de vida.

\section{Considerações Finais}

De acordo com a Teoria de Capital Humano, segundo Schultz (1963, apud ZIMMER, 2011), a educação é um investimento por meio do qual se adquire capacitações, que, por sua vez, proporcionarão satisfações futuras ao incrementar os rendimentos. Essa teoria mostrou-se válida através da análise realizada por Barbosa Filho e Pessôa (2008). O estudo revelou taxas de retorno da educação no Brasil extremamente elevadas, o que significa que o aumento de salário está relacionado ao maior número de anos de escolaridade.

A pesquisa realizada neste trabalho caminhou para o mesmo entendimento. Os resultados encontrados comprovam que a base da pirâmide de São Paulo acredita que o maior nível de instrução culmina, de maneira geral, em um melhor cargo e/ou emprego, o qual proporcionará maior renda e melhores condições de vida. Assim, é percebido por essa camada da sociedade que a educação é, de fato, importante.

Depois de alinhar o entendimento teórico $e$ o discernimento da base da população referente à importância da educação, buscou-se entender o que 
é feito, na prática, pelas pessoas para incrementarem suas situações. Muitos dos respondentes afirmaram que se pudessem, parariam de trabalhar para retomar os estudos. Contudo, a necessidade de trabalhar não é um fator excludente da educação, pois muitas pesssoas trabalham e estudam ao mesmo tempo. E outros indivíduos responderam que mesmo tendo condições, não retornariam à escola.

Quando indagadas a respeito de suas atitudes e cobranças em relação aos filhos, as pessoas ratificaram a importância dos estudos ao responderem, em sua grande maioria, que gostariam que seus filhos completassem o Ensino Médio ou Superior. Dessa forma, com a pressão dos pais e da sociedade, a população da base da pirâmide está ficando mais instruída. De acordo com o Data Popular (2006), nota-se um aumento da média de anos de escolaridade das classes populares. E constatou-se que os indivíduos mais novos possuem maior nível educacional que os de mais idade, conforme os resultados da pesquisa.

A importância dos estudos é impulsionada por ações do governo, como o programa Bolsa Família. Esse programa ajuda financeiramente as famílias de baixa renda, porém, impõe uma condição ao recebimento do auxílio: as crianças devem frequentar a escola regularmente (MAIA, 2008). A educação também é estimulada na tentativa de afastar a sensação de exclusão da população de baixa renda. Pessoas que não têm condições de acompanhar a cultura consumista, na qual o Brasil está inserido, sentem-se à margem da sociedade. Como apresentado no Referencial Teórico, Oliveira (2006) afirma que o consumo faz a população de baixa renda se sentir pertencente a um grupo, como parte integrante da sociedade, melhorando a autoestima, e diminuindo, o sentimento de exclusão $e$ de inferioridade. Assim, para poder consumir mais, os indivíduos necessitam de rendas maiores, o que leva à busca de melhores empregos. Cargos e empregos com salários maiores são geralmente decorrentes de um maior grau de instrução. Observa-se, então, a necessidade da educação para se elevar o bem-estar da sociedade.

Em relação ao futuro, a maior parte dos respondentes pretende retomar ou continuar os estudos, e acredita que assim, suas condições de vida nos próximos anos melhorarão significativamente. As pessoas de renda mais elevada são mais otimistas em relação ao futuro, se comparadas com os indivíduos de renda mais baixa. Essa mesma conclusão foi obtida por pesquisa realizada pelo IPEA sobre as expectativas das famílias brasileiras. (IPEA, 2012)

Portanto, a confrontação dos dados secundários, obtidos a partir de teorias e estudos empíricos, com dados primários, resultantes de pesquisa exploratória, possibilitou concluir que a base da pirâmide do município de São Paulo está ciente que a educação é um instrumento fundamental para o acréscimo da renda. Por meio desses resultados foi possível atingir os objetivos inicialmente propostos e analisar cada uma das hipóteses, conforme descrito ao longo das análises e apresentado resumidamente a seguir:

\begin{tabular}{l|l}
\multicolumn{1}{|c|}{ HipóteSES E OBJETIVos A SEREM PESQUiSADOS } & StATUS \\
\hline $\begin{array}{l}\text { H0: A população da base da pirâmide tem } \\
\text { conhecimento da relação entre uma maior } \\
\text { renda e a quantidade de educação adquirida. }\end{array}$ & $\begin{array}{l}\text { Hipótese } \\
\text { confirmada }\end{array}$ \\
\hline $\begin{array}{l}\text { H1: A população de baixa renda } \\
\text { reconhece a importância da educação. }\end{array}$ & $\begin{array}{l}\text { Hipótese } \\
\text { confirmada }\end{array}$ \\
\hline $\begin{array}{l}\text { H2: O aumento de renda proporcionado pelo } \\
\text { maior nível educacional é um motivador para } \\
\text { que se dê maior importância aos estudos. }\end{array}$ & $\begin{array}{l}\text { Hipótese } \\
\text { confirmada }\end{array}$ \\
\hline $\begin{array}{l}\text { H3: Devido ao aumento de renda } \\
\text { proporcionado pelo maior nível educacional, } \\
\text { as pessoas de baixa renda pretendem retomar } \\
\text { / continuar os estudos depois de adultos. }\end{array}$ & $\begin{array}{l}\text { Hipótese } \\
\text { parcialmente } \\
\text { confirmada }\end{array}$ \\
\hline $\begin{array}{l}\text { H4: A população da base da pirâmide acredita } \\
\text { na relação entre educação e melhores empregos. }\end{array}$ & $\begin{array}{l}\text { Hipótese } \\
\text { confirmada }\end{array}$ \\
\hline $\begin{array}{l}\text { H5: A expectativa da população de baixa } \\
\text { renda para os próximos anos é que suas } \\
\text { condições de vida melhorem de acordo } \\
\text { com a dedicação aos estudos. }\end{array}$ & $\begin{array}{l}\text { Hipótese } \\
\text { confirmada }\end{array}$ \\
\hline $\begin{array}{l}\text { H6: Devido ao aumento de renda proporcionado } \\
\text { pelo maior nível educacional, as pessoas de } \\
\text { baixa renda exigem que seus filhos estudem. }\end{array}$ & $\begin{array}{l}\text { Hipótese } \\
\text { confirmada }\end{array}$ \\
\hline & \\
\hline
\end{tabular}

Quadro 1: Resumo das hipóteses da pesquisa

Fonte: Elaborada pelos autores deste artigo

O trabalho carrega limitações teóricas e metodológicas. A principal limitação tem caráter metodológico e refere-se à necessidade de se restringir o tamanho da amostra e a localização da realização da pesquisa de campo, de forma intencional, buscando a viabilidade da pesquisa. O escopo não pôde explorar toda a diversidade do Brasil, não permitindo a extrapolacão dos dados obtidos e a generalização do comportamento da base da pirâmide com relação à renda e educação, 
a partir destes dados. Parte da amostra foi adotada devido à conveniência, sendo os elementos escolhidos com base na localização e na facilidade de encontro de indivíduos das classes $\mathrm{C}, \mathrm{D}$ e E. Esse método amostral possui desvantagens advindas da tendenciosidade da seleção e torna a representação da população menos realista.

É sugestão para pesquisas futuras, analisar separadamente as classes $\mathrm{C}$, D e E e confrontar as evidências e preferências de cada um destes segmentos, ao invés de tratá-los de forma consolidada como foi feito nesta pesquisa. Também seria importante aumentar a amostra, o que implicaria em um menor nível de erro. Uma maior pulverização de localidades e a obteção de mais respostas de indivíduos das classes $\mathrm{D}$ e E também são necessárias a fim de tornar o trabalho mais rico e condizente com a realidade.

Apesar das limitações aqui apresentadas, entende-se que este estudo exploratório foi bem-sucedido, pois ofereceu indícios de que a educação é um fator que proporciona o aumento de renda para a população mais pobre, sendo um estímulo para que a educação seja valorizada. Além disso, a pesquisa apresentou resultados importantes para a Academia e a sociedade em geral, relacionando assuntos referentes à educação e seus impactos diretos na renda da base da pirâmide, aprofundando o entendimento da situação dessas pessoas no passado, presente e suas expectativas para o futuro.

\section{REFERÊNCIAS}

BARBOSA FILHO, Fermando de Holanda; PESSÔA, Samuel. Retorno da educação no Brasil. Pesquisa e Planejamento Econômico, v. 38, n. 1, abr. 2008.

BEZERRA, Sandra. Instituto Data Popular: $57 \%$ da classe $\mathrm{C}$ pretendem comprar imóvel nos próximos dois anos. Câmara Brasileira da Indústria da Construção CBIC, 2012. Disponível em: < http://www.cbic.org.br/salade-imprensa/noticia/instituto-data-popular-57-da-classe-cpretendem-comprar-imovel-nos-proximos $>$. Acesso em: 6 maio 2012.

\section{CETELEM BGN, Grupo BNP Paribas. O Observador}

Brasil 2012. 2011. Disponível em: < http://www.cetelem. com.br/portal/Sobre_Cetelem/Observador.shtml>. Acesso em: 30 abr. 2012.
CONFEDERAÇÃO NACIONAL DE TRABALHADORES EM EDUCAÇÃO - CNTE. Acesso mais democrático à educação distribui a renda. 2007. Disponível em: < http://www.cnte.org.br>. Acesso em: 25 maio 2012.

\section{DATA POPULAR. O mercado da base da pirâmide no}

Brasil. 2006. Disponível em: < http://www.datapopular. com.br/> . Acesso em: 19 maio 2012.

DOUAT, Joanna Carolina Guarita. Avaliação do padrão socieconômico como indicador do perfil do consumo de mídia na sociedade brasileira. São Paulo, 2011. Dissertação, Escola de Administração de Empresas de São Paulo da Fundação Getúlio Vargas. 2011. $96 \mathrm{f}$.

FUNDAÇÃO GETÚLIO VARGAS. Centro de Políticas Sociais. De volta ao país do futuro: projeções, crise européia e a nova classe média. Rio de Janeiro, 2012. Disponível em: <http://www.fgv.br/cps/ncm2014/> . Acesso em: 30 abr. 2012.

\section{GIOVINAZZO, Renata A. Um estudo sobre o} desempenho e a estratégia das empresas que atuam no mercado de bens populares no Brasil.

Dissertação (Mestrado em Administração de Empresas)

- Departamento de Administração da Faculdade

de Economia, Administração e Contabilidade da Universidade de São Paulo. São Paulo, 2003. 144 f.

\section{INSTITUTO BRASILEIRO DE GEOGRAFIA E} ESTATÍSTICA - IBGE. Indicadores Sociais Municipais 2010: uma análise dos resultados do Universo do Censo Demográfico 2010. Estudos e Pesquisas Informação Demográfica e Socieconômica, Rio de Janeiro, n. 28, 2011.

\section{INSTITUTO BRASILEIRO DE GEOGRAFIA E} ESTATÍSTICA - IBGE. Censo Demográfico 2010. Disponível em: <http://www.ibge.gov.br/estadosat/temas. php? sigla $=$ sp\&tema $=$ resultuniverso_censo201 $>$. Acesso em: 9 jun. 2012.

INSTITUTO DE PESQUISA ECONÔMICA APLICADA IPEA. Gastos com a política social: alavanca para o crescimento com distribuição de renda. Comunicado n. 75, 2011. 
INSTITUTO DE PESQUISA ECONÔMICA APLICADA - IPEA. Índice de Expectativa das Famílias (IEF). 2012.

INSTITUTO DE PESQUISA ECONÔMICA APLICADA - IPEA. Situação Social dos Estados - São Paulo. Brasília, DF, 2012.

LOPES, Luis Felipe Dias. Apostila: estatística. Universidade Federal de Santa Maria, 2003. Disponível em: <http://www.scribd.com/doc/23835378/87/

TAMANHO-DA-AMOSTRA > . Acesso em: 8 jun. 2012.

MAIA, Adriana Silva. Efeitos do Programa Bolsa Família na redução da pobreza e distribuição de renda. International Policy Centre for Inclusive Growth, 2008. Disponível em: < http://www.ipc-undp.org/ publications/mds/46P.pdf > . Acesso em: 20 maio 2012.

MALHOTRA, Naresh K. Pesquisa de marketing: uma orientação aplicada. 4. ed. São Paulo: Bookman, 2004.

MELLO, Andréa N. de; OLIVEIRA, Eduardo M. R. de; SOUZA, Rafael N. G. de. O consumidor da classe "C" e seu comportamento de compra em relação às categorias de higiene pessoal, bebidas $e$ eletro-eletrônicos. Trabalho de Conclusão de Curso (MBA Executivo Internacional) - Fundação Instituto de Administração. São Paulo, 2008. 57 f.

OLIVEIRA, Mariana. A base da pirâmide torna-se o topo das vendas. Mundo do Marketing. [2012]. Disponível em: <http://mundodomarketing.com.br/>. Acesso em: 19 maio 2012.

PRAHALAD, C. K. A riqueza na base da pirâmide: como erradicar a pobreza com o lucro. Bookman, 2008.

SPERS, Renata G. et al. Desafios e oportunidades no setor de cartões de crédito: proposição de estratégias para o mercado popular. REGE - Revista de Gestão USP, Programa de Pós-graduação em Administração da Faculdade de Economia e Contabilidade, Universidade de São Paulo, São Paulo, 2008.

SPERS, Renata Giovinazzo; VICTOR, Bart; FISCHER,

Edward $F$. The competitive advantage of communities at the bottom of the pyramid. Working Paper V3. Vanderbilt University, 2010.
SPERS, Renata Giovinazzo; WRIGHT, James Terence Coulter. Mercado de bens populares no Brasil: desempenho e estratégia das empresas. Anais do EnANPAD, Salvador, 2006.

WRIGHT, James Terence Coulter; SPERS, Renata Giovinazzo. Mercado popular no Brasil: abordagens para geração de negócios e casos de sucesso. São Paulo: Blucher, 2011.

ZIMMER, Roberto. As relações entre educação, geração de renda e ocupações no Estado do Rio Grande do Sul. Dissertação. Universidade Federal do Rio Grande do Sul, Faculdade de Ciências Econômicas, Programa de Pós-Graduação em Economia. Porto Alegre, 2011. $89 \mathrm{f}$. 